\title{
Review of Turn around Point Long Period Fiber Gratings
}

\author{
Monika Gambhir, Shilpi Gupta \\ Department of Electronics \& Communication Engineering, SVNIT, Surat, India \\ Email: gambhirmonika9@gmail.com, shilpi_ec@yahoo.com
}

Received 2 December 2015; accepted 24 December 2015; published 30 December 2015

Copyright (C) 2015 by authors and Scientific Research Publishing Inc.

This work is licensed under the Creative Commons Attribution International License (CC BY). http://creativecommons.org/licenses/by/4.0/

(c) (i) Open Access

\begin{abstract}
Long period fiber gratings are emerging as a potential candidate in the list of surrounding refractive index optical fiber sensors. Their sensitivity can be enhanced greatly if the grating period, fiber dimensions and surrounding refractive index are optimized in a way to operate at a point called turn around point on phase matching curves of these gratings. Turn around point LPFGs are well known for their ultrahigh sensitivity to external parameters. Potential of operating LPFG at or near turn around point has been investigated by many researchers in various applications including physical parameter sensing, adulteration detection, radiation dose, etc. Since TAP LPFGs are in investigation phase therefore a lot of rigorous $\&$ efficient work in finding techniques for optimizing their potential as sensor in chemical, biochemical, structural health monitoring is still to be carried out. A brief review of work carried out in this domain till now is presented here and key findings from literature review are highlighted.
\end{abstract}

\section{Keywords}

LPFG (Long Period Fiber Grating), TAP (Turn around Point), SRI (Surrounding Refractive Index), LP (Linearly Polarized)

\section{Introduction}

Long period fiber gratings are passive optical fiber sensors emerged in recent years. There are mainly two types of Index (refractive index) gratings in fiber optics: FBG (Fiber Bragg Gratings) \& LPFG (Long Period Fiber Gratings). Structurally, both types of gratings are identical except that the periods of Fiber Bragg gratings are two orders of magnitude smaller than those of LPGs. FBGs induce contra directional coupling. Light energy from forward propagating modes is transferred to modes traveling in the opposite direction. FBGs are often referred to as short period, reflection gratings because of this effect. LPFGs, on the other hand, couple energy 
co-directionally. Energy from the forward propagating incident modes is transferred to either forward propagating cladding or radiation modes depending on the structure of the waveguide [1]-[6].

Fiber Bragg gratings have already proved their excellence in physical parameter sensing, e.g. temperature, strain, torsion, bend, etc. and in many practical applications including structural health monitoring which is required for existing smart world era [7]. LPFGs are known to have high refractive index sensitivity in comparison to its counterpart Fiber Bragg Gratings. The evanescent field of coupled mode that extends more into the surroundings in LPFGs enables it to be used as a significant surrounding refractive index sensor.

Sensitivity of these gratings greatly depends upon the choice of grating period. Dispersion curves drawn between resonance wavelength $\left(\lambda_{\text {res }}\right)$ and grating period $(\Lambda)$ for higher order cladding modes indicate the presence of turn around point where the slope of the curve changes sign from positive to negative. LPFGs fabricated at

these turn around points appear to be ultrahigh sensitive as the slope $\frac{\mathrm{d} \lambda_{\text {res }}}{\mathrm{d} \Lambda}$ of the dispersion curve is infinite.

For lower order modes these turn around points occur at higher wavelengths outside the optical communication window. The possibility of interaction of evanescent field with surroundings improves with increase in order of the cladding mode being coupled to the fundamental mode due to larger coupling coefficients [8].

In this paper, systematic review of the LPFGs operating at turn around point is presented. Section 2 highlights the presence and significance of turn around points that exist on the characteristic curves of cladding modes. Fabrication techniques, methods used for tuning of turn around point have also been discussed in this section. Reported applications of TAP LPFGs have been summarized in Section 3. Section 4 provides an overview of thin film coated LPFGs and recently reported applications of thin film coated LPFGs operating at turn around points. The paper is concluded in Section 5.

\section{Ultrahigh Sensitive TAP LPFGs}

Periodic modulation of refractive index in optical fiber causes coupling of fundamental core mode with either co-propagating or counter propagating cladding modes. Coupling of co-propagating fundamental guided mode $\mathrm{LP}_{01}$ and cladding modes represented by $\mathrm{LP}_{0 \mathrm{~m}}$ takes place in long period gratings according to the phase matching condition, which results in series of attenuated resonance peaks in transmission spectrum. The phase matching condition is given by

$$
\beta_{01}-\beta_{c l, m}=\frac{2 \pi}{\Lambda}
$$

where $\beta_{01}$ is propagation constant of the fundamental mode, $\beta_{c l . m}$ is propagation constant of $m^{\text {th }}$ cladding mode and $\Lambda$ is period of grating. Long period fiber grating sensor configuration shown in Figure 1 represents the presence of evanescent field of coupled modes that can interact with surroundings.

Mathematical expressions derived in [8] for calculating shift in resonance wavelength with respect to change in surrounding refractive index is given by

$$
\frac{\mathrm{d} \lambda_{\text {res }}}{\mathrm{d} n_{\text {surr }}}=\lambda_{\text {res }} \cdot \gamma \cdot \Gamma_{\text {res }}
$$

where $\lambda_{\text {res }}$ is resonance wavelength, $n_{\text {surr }}$ is surrounding refractive index, $\gamma$ is general waveguide dispersion and $\Gamma_{\text {res }}$ represents surrounding refractive index dependence on waveguide dispersion respectively. Slopes of the phase matching curves drawn for B/Ge co-doped fiber, with cladding modes of order $m=8$ to 20 change their sign from positive to negative at points called turn around points as indicated in Figure 2. These points offer ultrahigh sensitivity because a change in wavelength corresponding to change in grating period is infinite. Grating period may change due to change in effective refractive indices of modes which also depends on surrounding refractive index. Therefore any small change in surrounding refractive index may cause significant shift in resonance wavelength. If $\Lambda$ is short, the phase matching curves corresponding to coupling between core and higher order cladding modes are parabolas over the wavelength range of 800 - $2000 \mathrm{~nm}$ [8]-[11].

Phase matching curves plotted between grating period and wavelength are essential in analysis of long period fiber gratings. Existence of turnaround point in the phase matching curves was revealed for first time in [8]. Coupling to higher order cladding modes increases sensitivity to surrounding refractive index because of extension of evanescent field in surrounding with increase in cladding mode order. Moreover coupling strength of 


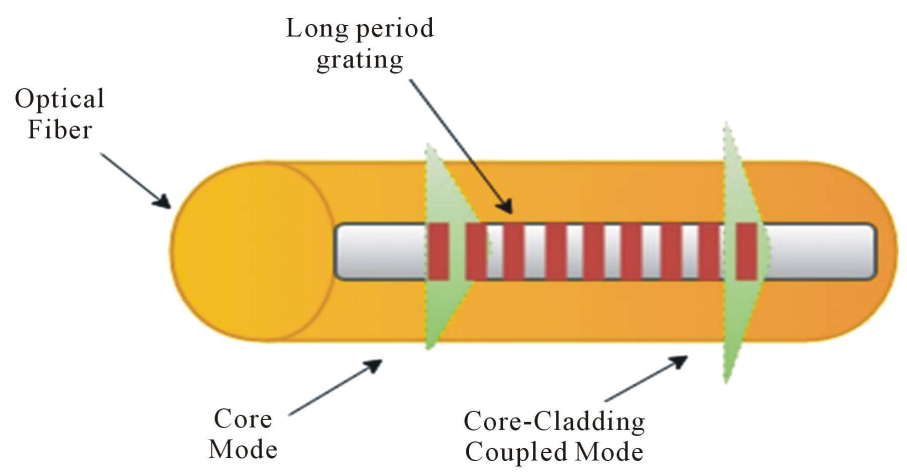

Figure 1. Long period fiber grating refractive index sensor.

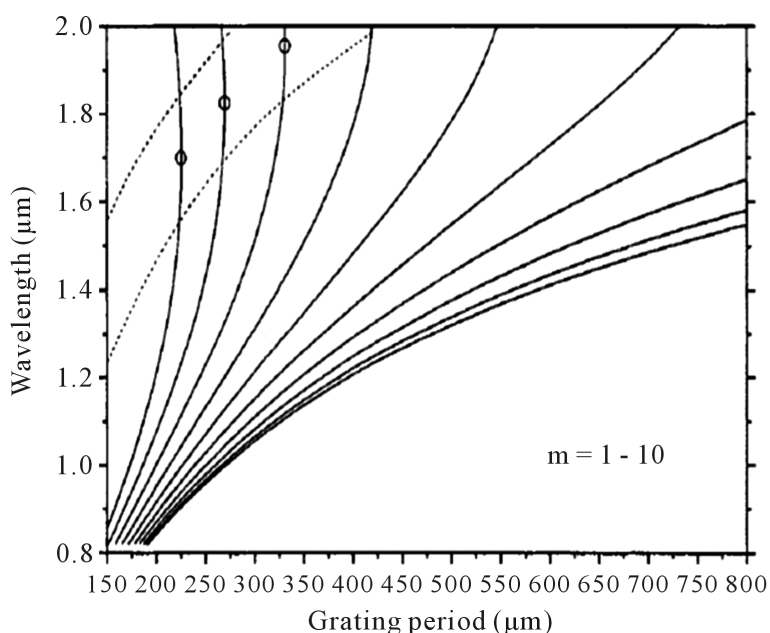

(a)

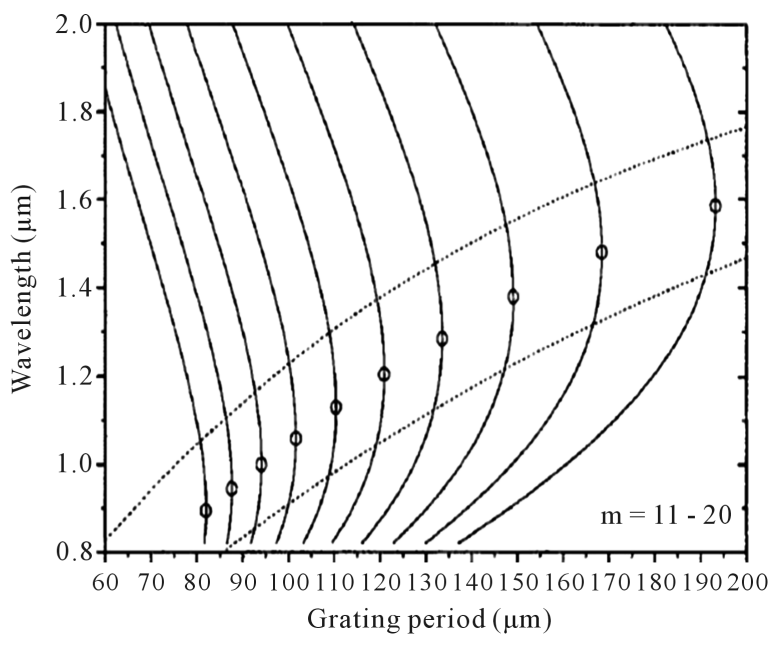

(b)

Figure 2. Phase matching curves (a) Modes $m=1$ to $m=10$ (b) Modes $m=11$ to $m=20$ [8].

fundamental mode and odd order cladding modes is better as compared to that with even order cladding modes. This is because odd order cladding modes have a peak of intensity that lies in the core. Transmission spectra of Long period fiber gratings designed to operate at TAP indicate that any change in SRI causes change in peak attenuation at resonant wavelength which opens the possibility of simple \& easy amplitude based demodulation technique. Further, if the SRI is more than refractive index of air i.e. if LPFG is immersed in a liquid, there are two resonant wavelengths in transmission spectrum and change in SRI causes shift in these two resonant wavelengths \& therefore wavelength based demodulation can be used at the expense of decrease in sensitivity.

LPFG with grating period $205 \mu \mathrm{m}$, in which coupling of $\mathrm{LP}_{0,11}$ mode with fundamental $\mathrm{LP}_{01}$ takes place exactly at turn around point, is reported in [12]. Designed grating is used for fuel adulteration detection. Single attenuation peak splits into two when grating is immersed in petrol having refractive index greater than 1.0 which is in line with [8]. Reducing cladding diameter of LPFG operated near TAP greatly enhances the sensitivity [13]. LPFG with a grating period of $165 \mu \mathrm{m}$ in SMF-28e fabricated which results in coupling of fundamental mode with $\mathrm{LP}_{0,12}$ cladding mode. Figure 3 depicts transmission spectra of LPFG with SRI 1.0 and 1.333, after reducing the cladding diameter to different values [14]. It may be observed that transmission depth decreases with the increase in reduction of the cladding diameter and single attenuation peak splits into two when SRI is more than 1.

Grating period of less than $250 \mu \mathrm{m}$ is required to enable coupling to higher order cladding modes. Therefore sophisticated techniques with high precision are required for fabrication of fiber gratings at turnaround points. $\mathrm{CO}_{2}$ laser scanning [12] [15]-[19], KrF excimer Laser [8] [14] [20]-[23] \& Femtosecond laser [24]-[26] fabrication techniques have been used for fabrication of turn around or near turn around point long period fiber grating fabrication in different types of fibers. Recently TAP LPFG has been fabricated using KrF excimer laser in [9]. Gratings fabricated by $\mathrm{CO}_{2}$ scanning are thermally stable \& require no post processing technique in long period 


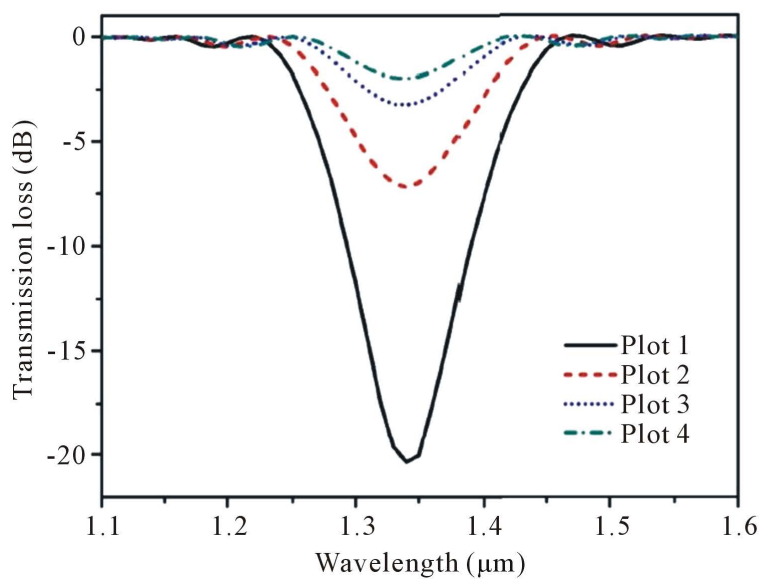

(a)

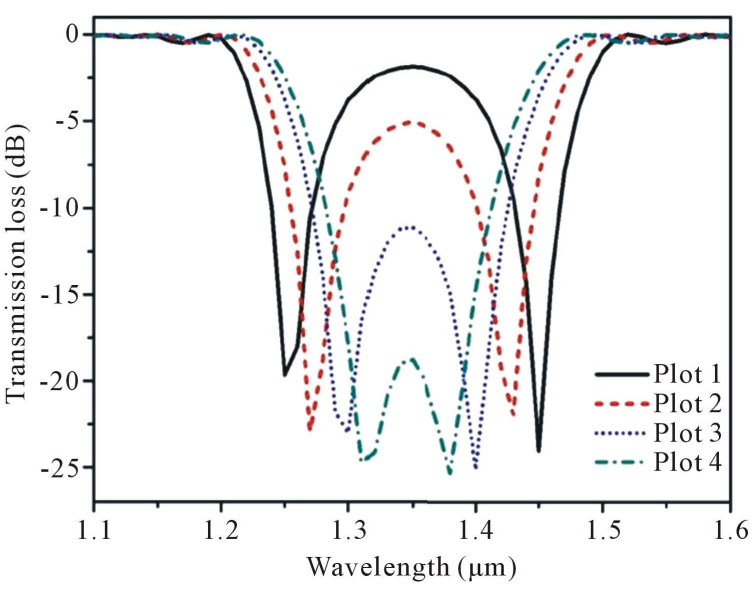

(b)

Figure 3. (a) Transmission Spectra of cladding ethed LPFG in air (b) Transmission Spectra of cladding ethed LPFG in water (Plot 1: TAP 20 dB, Plot 2: TAP 7 dB, Plot 3: TAP 3 dB, Plot 4: TAP 2 dB) [14].

gratings. Operating LPFG exactly at TAP requires high precision in fabrication, a slight change in effective refractive indices of modes cause turn around point to shift. Exposure to UV [27], Gamma radiation [16], taper tuning [16], etching of cladding [14], overlay coating [28] is reported for tuning of long period grating at turn around point. Investigation of transmission spectra of LPFG is also carried out in photonic crystal fibers [25] [26] apart from standard single mode \& photosensitive fibers.

\section{Refractometric Sensors based on TAP LPFG}

Propagation characteristics of modes in optical fiber with long period fiber gratings are strong function of the refractive index of surrounding medium. These refractometric sensors have attracted attention in the field of food quality control, structural health monitoring and biomedical applications recently.

Performance of Turnaround point LPFGs have been investigated in a variety of applications including temperature, strain \& refractive index sensitivity. Errors in refractive index sensing may result due to temperature variations that needs to be considered. Temperature compensated TAP LPFG have also been reported in [23].

Fuel adulteration detection results using non TAP LPFG [20] \& TAP LPFG [12] have been presented to depict the ultrahigh sensitivity of TAP LPFGs. Transmission spectra shown in Figure 4 \& Figure 5 indicate that sensitivity of non TAP LPFG is $0.6 \mathrm{~nm} / \%$ \& that of TAP LPFG is $0.949 \mathrm{~nm}$ per percentage change in concentration of kerosene in petrol from 0 to $10 \%$. Slight improvement in sensitivity is obtained by reducing cladding diameter as indicated in Figure 4(b).

Ultra high sensitivity of turn around point long period gratings can be used for improving the adulteration detection of the edible food products like oils, milk. Appreciably high sensitivity of turnaround point long period gratings in different applications have been summarized in Table 1.

\section{Thin Film Coated TAP LPFGs}

Sensitivity of long period gratings can be improved by coating thin films of nm thickness and having refractive index greater than that of silica. Figure 6 shows four layer model used for analysis of thin film coated LPFGs with core, cladding, overlay and surroundings as each layer of the structure having refractive indices $n_{1}, n_{2}, n_{3}$ and $n_{4}$ respectively. Long period gratings offer appreciable shift in wavelength towards longer wavelengths when the SRI is less than that of the cladding \& is attributed to total internal reflection.

When SRI is more than that of cladding, shift is towards shorter wavelengths and is quite small to be considered for demodulation. The reduced sensitivity of LPFG when SRI is greater than cladding is attributed to weak Fresnel's reflections. This can be enhanced by nm thick layers of thin films of high refractive index materials, e.g. tricosenoic acid, titanium dioxide, PDDA polymer, etc. [29]-[34].

Coating of thin film material on long period fiber grating increases effective refractive indices of the cladding modes. After certain thickness of the film, cladding modes become guided in the overlay hence evanescent field 


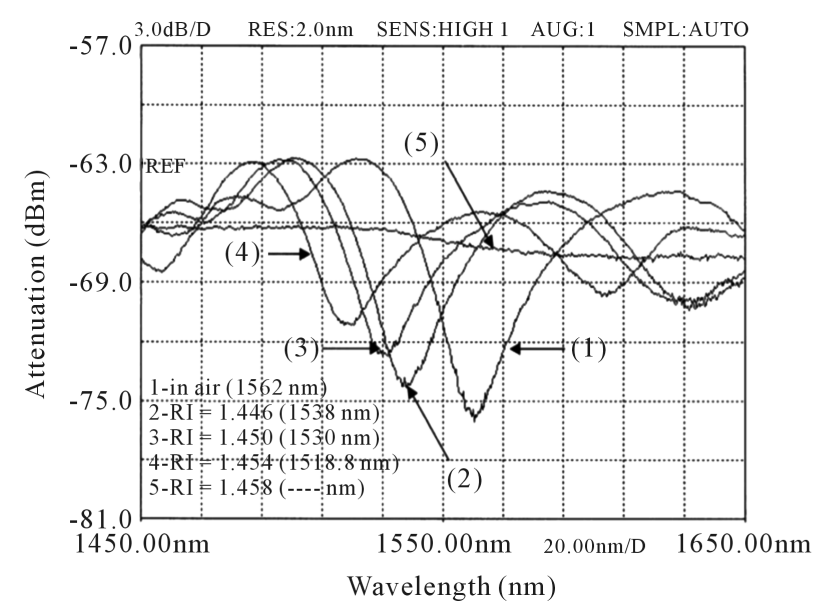

(a)

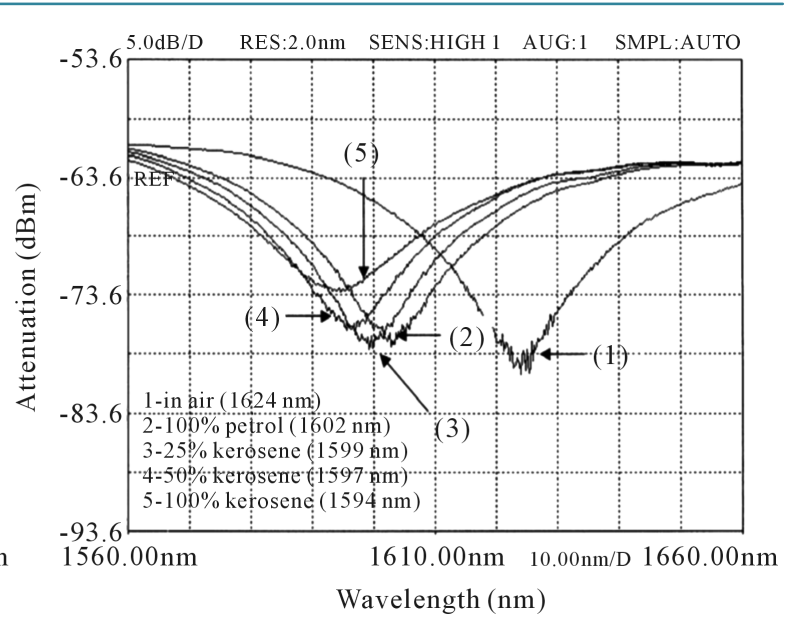

(b)

Figure 4. (a) Transmission Spectra of LPFG with different Kerosene in petrol (b) Transmission Spectra of ethed LPFG with different percentage of Kerosene in petrol [20].

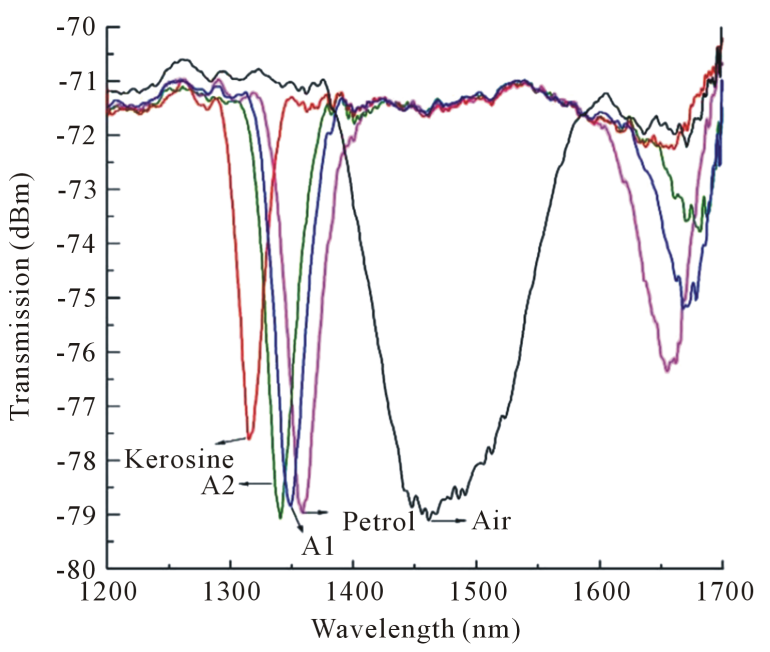

(a)

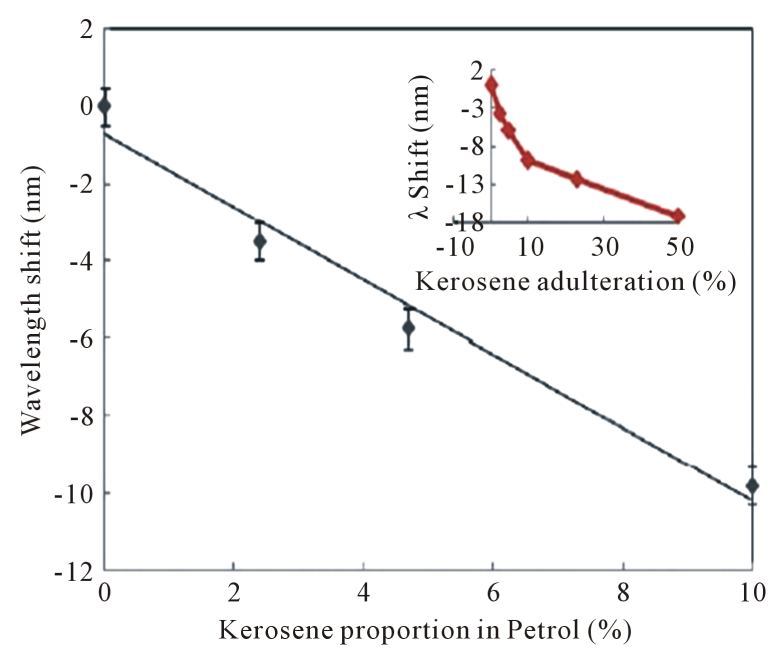

(b)

Figure 5. (a) Transmission Spectra of TAP LPFG with different percentage of Kerosene in petrol A1: 10\%, A2: 50 \% (b) Shift in TAP LPFG resonance peak as a function of Kerosene in petrol [12].

Table 1. Reported TAP LPFGs for various applications.

\begin{tabular}{|c|c|c|c|c|c|c|}
\hline Type of Fiber & $\begin{array}{l}\text { Grating } \\
\text { Period }\end{array}$ & $\begin{array}{l}\text { TAP/Near } \\
\text { TAP }\end{array}$ & $\begin{array}{l}\text { Cladding } \\
\text { Mode }\end{array}$ & $\begin{array}{l}\text { Detection } \\
\text { Range }\end{array}$ & Application & Sensitivity \\
\hline B/Ge co-doped SMF & 208 & TAP & $\mathrm{LP}_{0,11}$ & $1.397-1.432$ & Fuel Adulteration & $\begin{array}{l}0.949 \mathrm{~nm} / \% \text { change in } \\
\text { Kerosene in Petrol }\end{array}$ \\
\hline SMF-28e & 165 & TAP & $\mathrm{LP}_{0,12}$ & $1.335-1.360$ & SRI Sensitivity & 1847 nm/RIU \\
\hline B/Ge codoped SMF & 206 & Near TAP & $\mathrm{LP}_{0,11}$ & 6 - 65 KGy & $\begin{array}{c}\text { Gamma radiation } \\
\text { dose }\end{array}$ & $\begin{array}{l}80 \mathrm{~nm} \text { for } 65 \mathrm{KGy} \\
\& 35 \mathrm{~nm} \text { for } 6 \mathrm{KGy}\end{array}$ \\
\hline SMF-28 & 230.89 & TAP & Not Specified & $1.333-1.353$ & $\begin{array}{l}\text { Tempaerature, Strain } \\
\text { \& SRI Sensitvity }\end{array}$ & $\begin{array}{c}1.63 \mathrm{~nm} /{ }^{\circ} \mathrm{C}, 37 \mathrm{pm} / \mu \varepsilon \\
\quad \& 2500 \mathrm{~nm} / \mathrm{RIU}\end{array}$ \\
\hline B/Ge co-doped SMF & 180 & TAP & $\mathrm{LP}_{0,12}$ & $325-1300 \mu \varepsilon$ & Strain & $1.77 \mathrm{~dB} / \mu \varepsilon$ \\
\hline B/Ge codoped SMF & 206 & Near TAP & $\mathrm{LP}_{0,11}$ & $0-1300 \mu \varepsilon$ & Strain & $1.33 \mathrm{~dB} / \mu \varepsilon$ \\
\hline
\end{tabular}


of guided modes having significant energy is available near the surrounding for interaction. The reorganization of modes depends on overlay material thickness \& refractive index and also on surrounding refractive index. The transition of modes occurs faster for higher refractive index overlays [34]-[36]. Transmission spectra of thin films of various refractive indices \& thickness on LPFG are analyzed in [30].

Temperature compensated chemical sensor using silica nano particles as overlay is reported in [37]. Coating is done on a pair of cascaded turnaround point long period fiber gratings. Detection of very low concentration Escherichia coli bacteria with ultra high sensitivity of $2321 \mathrm{~nm} / \mathrm{RIU}$ is reported in [38]. In [39] $\mathrm{Al}_{2} \mathrm{O}_{3}$ is used as nano film material and transition region found to be in range $1.4524-1.461$ with $3000 \mathrm{~nm} / \mathrm{RIU}$ for $100 \mathrm{~nm}$ thickness of overlay which might not be possible with uncoated LPFG as shown in Figure 7(a). With further increase in thickness, transition region shifts to lower refractive index range. Long period gratings operating at TAP and coated with thin films of high refractive index materials have been reported in [34] [37]-[42] for chemical/biochemical sensing applications.

TAP LPFG coated with (PDDA/SiO $)_{10}$ film has been investigated for sensitivity to Ammonia in water. Transmission spectra with different concentrations of Ammonia indicated in Figure 7(b). The minimum detection level is found to be $0.14 \mathrm{ppm} \&$ response time of sensor is approximately 100 seconds [34]. Filtering characteristics of single and multiple, $\pi$ phase shifted, thin film coated turn around point LPFGs have been simulated and analyzed in [43]. Parameters obtained need to be optimized for a particular application.

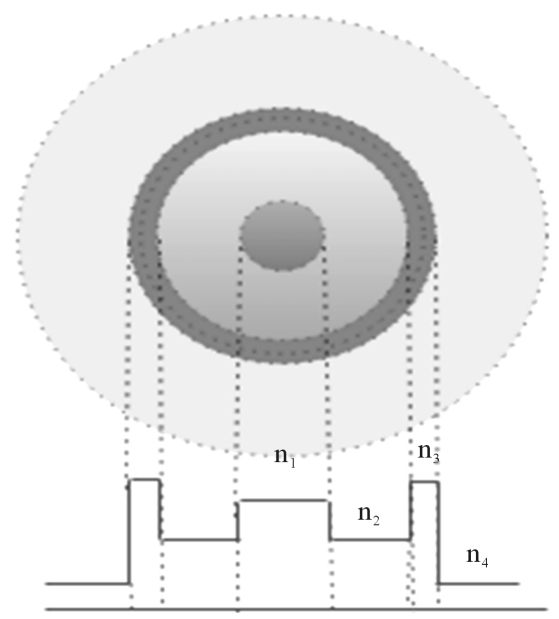

Figure 6. Four layer geometry for thin film coated LPFGs.

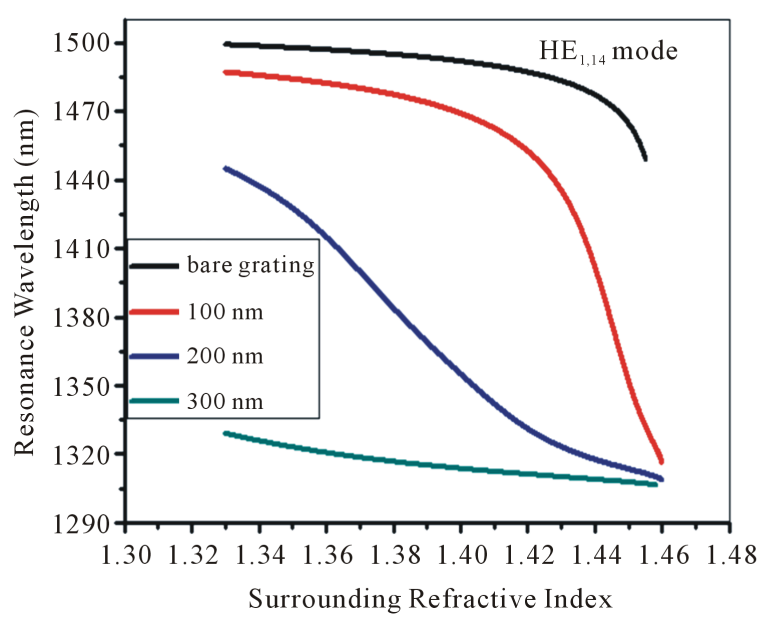

(a)

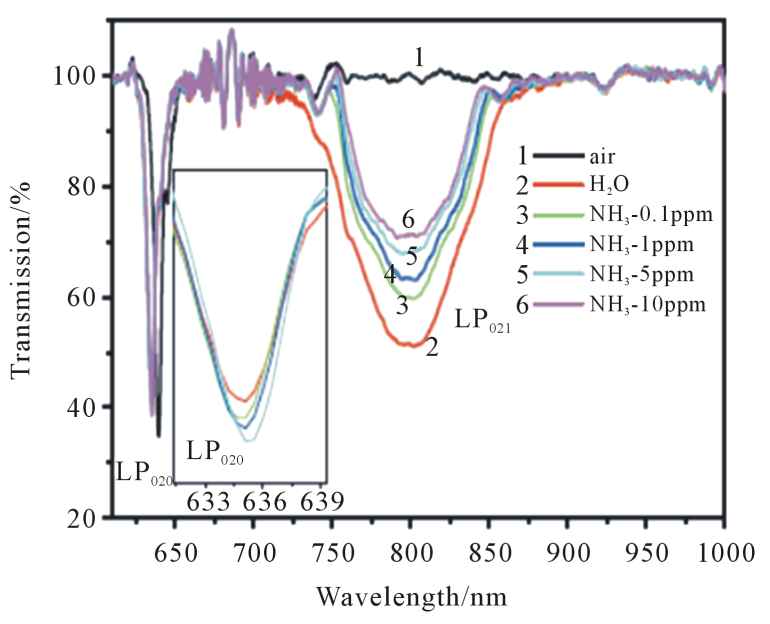

(b)

Figure 7. Response of resonance wavelength for different $\mathrm{Al}_{2} \mathrm{O}_{3}$ nano film thickness [39] (b) Transmission spectra of thin film coated PMTP LPFG for different Ammonia Concentration in water [34]. 


\section{Conclusion}

SRI sensitivity improvement of TAP LPFGs can be observed in terms of significant wavelength shift \& amplitude variations of the attenuation bands enabling use of wavelength and amplitude based on demodulation techniques respectively. Most of the SRI sensors based on long period operating at turn around points have been investigated in applications where the SRI is less than that of cladding. To operate these gratings as sensors in applications with SRI greater than that of cladding, coating of high refractive index materials can be done, which causes reorganization of the cladding modes and enhances the possibility of surrounding region to interact with evanescent field of cladding modes. Efficient optimization techniques for overlay material thickness and its refractive index for tuning the transition region in desired refractive index range are required to utilize LPFG in commercial applications. Further variation in physical parameters may result in false readings so some compensation techniques for these parameters are also required to be analyzed and implemented carefully. Performance of TAP LPFGs, thin film coated TAP LPFGs and a combination of these can be investigated in medical diagnostics, food quality control and biochemical hazard detection.

\section{References}

[1] Fidanboylu, K. and Efendioglu, H.S. (2009) Fiber Optic Sensors and Their Applications. 5th International Advanced Technologies Symposium (IATS’09), Karabuk, 13-15 May 2009, 1-6.

[2] Hill, K.O. and Meltz, G. (1997) Fiber Bragg Grating Technology Fundamentals and Overview. Journal of Lightwave Technology, 15, 1263-1276. http://dx.doi.org/10.1109/50.618320

[3] Miguel, J., Higuera, L. and Cobo, L.R. (2015) Fiber Optic Sensors in Structural Health Monitoring. Journal of Lightwave Technology, 29, 150-164.

[4] James, S.W. and Tatam, R.P. (2003) Optical Fibre Long-Period Grating Sensors: Characteristics and Application. Measurement Science Technology, 14, R49-R61. http://dx.doi.org/10.1088/0957-0233/14/5/201

[5] Patrick, H.J., Kersey, A.D. and Bucholtz, F. (1998) Analysis of the Response of Long period Fibre Gratings to External Index of Refraction. Journal of Lightwave Technology, 16, 1606-1612. http://dx.doi.org/10.1109/50.712243

[6] Akki, J.F., Lalasangi, A.S., Raika, P.U., Srinivas, T., Laxmeshwar, L.S. and Raikar, U.S. (2013) Core-Cladding Mode Resonances of Long Period Fiber Grating in Concentration Sensor. Journal of Applied Physics, 4, 41-46.

[7] Taghipour, A., Rostami, A., Bahrami, M., Baghban, H. and Dolatyari, M. (2014) Comparative Study between LPFGand FBG-Based Bending Sensors. Optics Communications, 312, 99-105. http://dx.doi.org/10.1016/j.optcom.2013.09.020

[8] Shu, X.W., Zhang, L. and Bennion, I. (2002) Sensitivity Characteristics of Long-Period Fiber Gratings. Journal of Lightwave Technology, 20, 255-266. http://dx.doi.org/10.1109/50.983240

[9] Besley, J.A., Wang, T. and Reekie, L. (2003) Fiber Cladding Mode Sensitivity Characterization for long-Period Gratings. Journal of Lightwave Technology, 21, 848-853. http://dx.doi.org/10.1109/JLT.2003.809577

[10] Hochreiner, H., Cada, M. and Wentzell, P.D. (2008) Modeling the Response of a Long-Period Fiber Grating to Ambient Refractive Index Change in Chemical Sensing Applications. Journal of Lightwave Technology, 26, 1986-1992. http://dx.doi.org/10.1109/JLT.2007.912022

[11] Koyamada, Y. (2001) Numerical Analysis of Core-Mode to Radiation-Mode Coupling in Long-Period Fiber Gratings. IEEE Photonics Technology Letters, 13, 308-310. http://dx.doi.org/10.1109/68.917834

[12] Kher, S., Chaubey, S., Kishore, J. and Oak, S.M. (2013) Detection of Fuel Adulteration with High Sensitivity Using Turnaround Point Long Period Fiber Gratings in B/Ge Doped Fibers. IEEE Sensors Journal, 13, 4482-4486. http://dx.doi.org/10.1109/JSEN.2013.2270312

[13] Kashyap, R. (2009) Fiber Bragg Gratings. Elsevier.

[14] Biswas, P., Basumallick, N., Bandyopadhyay, S., Dasgupta, K., Ghosh, A. and Bandyopadhyay, S. (2015) Sensitivity Enhancement of Turn-Around-Point Long Period Gratings by Tuning Initial Coupling Condition. IEEE Sensors Journal, 15, 1240-1245. http://dx.doi.org/10.1109/JSEN.2014.2361166

[15] Chaubey, S., Kher, S., Kishore, J. and Oak, S.M. (2014) $\mathrm{CO}_{2}$ Laser-Inscribed Low-Cost, Shortest-Period Long-Period Fiber Grating in B-Ge Co-Doped Fiber for High-Sensitivity Strain Measurement. Pramana, 82, 373-377. http://dx.doi.org/10.1007/s12043-014-0692-y

[16] Chaubey, S., Kher, S. and Oak, S.M. (2011) Radiation and Taper Tuning of Long Period Grating for High Sensitivity Strain Measurement. 7th Workshop on Fiber and Optical Passive Components (WFOPC), Montreal, 13-15 July 2011, 1-4. http://dx.doi.org/10.1109/wfopc.2011.6089670 
[17] Lan, X., Han, Q., Huang, J., Wang, H., Gao, Z., Kaur, A. and Xiao, H. (2013) Turn-Around Point Long-Period Fiber Grating Fabricated by $\mathrm{CO}_{2}$ Laser for Refractive Index Sensing. Sensors and Actuators B: Chemical, 177, 1149-1155. http://dx.doi.org/10.1016/j.snb.2012.12.006

[18] Lan, X., Han, Q., Wei, T., Huang, J. and Xiao, H. (2011) Turn-Around Point Long-Period Fiber Gratings Fabricated by $\mathrm{CO}_{2}$ Laser Point-by-Point Irradiations. IEEE Photonics Technology Letters, 23, 1664-1666. http://dx.doi.org/10.1109/LPT.2011.2166256

[19] Kher, S., Chaubey, S., Kashyap, R. and Oak, S.M. (2012) Turn-Around Point Long-Period Fiber Gratings (TAP-LPGs) as High-Radiation-Dose Sensors. IEEE Photonics Technology Letters, 24, 742-744. http://dx.doi.org/10.1109/LPT.2012.2187637

[20] Mishra, V., Jain, S.C., Singh, N., Poddar, G.C. and Kapur, P. (2008) Fuel Adulteration Detection Using Long Period Fiber Grating Sensor Technology. Indian Journal of Pure \& Applied Physics, 46, 106-110.

[21] Iadicicco, A., Paladino, D., Pilla, P., Campopiano, S., Cutolo, A. and Cusano, A. (2012) Ch. 14: Long Period Gratings in New Generation Optical Fibers. In: Yasin, M., Harun, S.W. and Arof, H., Eds., Recent Progress in Optical Fiber Research, InTech, 291-326. http://dx.doi.org/10.5772/27910

[22] Chiavaioli, F., Biswas, P., Trono, C., Bandyopadhyay, S., Giannetti, A., Tombelli, S., Basumallick, N., Dasgupta, K. and Baldini, F. (2014) Towards Sensitive Label-Free Immunosensing by Means of Turn-Around Point Long Period Fiber Gratings. Biosensors and Bioelectronics, 60, 305-310. http://dx.doi.org/10.1016/j.bios.2014.04.042

[23] Garg, R., Tripathi, S.M., Thyagarajan, K. and Bock, W.J. (2013) Long Period Fiber Grating Based TemperatureCompensated High Performance Sensor for Bio-Chemical Sensing Applications. Sensors and Actuators B: Chemical, 176, 1121-1127. http://dx.doi.org/10.1016/j.snb.2012.08.059

[24] Allsop, T., Kalli, K., Zhou, K., Lai, Y., Smith, G., Dubov, M., Webb, D.J. and Bennion, I. (2008) Long Period Gratings Written into a Photonic Crystal Fiber by a Femtosecond Laser as Directional Bend Sensors. Optics Communications, 281, 5092-5096. http://dx.doi.org/10.1016/j.optcom.2008.07.001

[25] Kanka, J. (2012) Design of Turn-Around-Point Long-Period Gratings in Ge-Doped Photonic Crystal Fibers for Evanescent Sensing. Proceedings of SPIE, 8426, 34-40. http://dx.doi.org/10.1117/12.923039

[26] Kanka, J. (2013) Design of Turn-Around-Point Long-Period Gratings in a Photonic Crystal Fiber for Refractometry of Gases. Sensors and Actuators B: Chemical, 182, 16-24. http://dx.doi.org/10.1016/j.snb.2013.02.048

[27] Shu, X., Zhu, X., Wang, Q., Jiang, S., Shi, W. and Huang, Z. (1999) Dual Resonant Peaks of LP Cladding Mode in Long-Period Gratings. Electronics Letters, 35, 649-651. http://dx.doi.org/10.1049/el:19990442

[28] Smietana, M., Koba, M., Mikulic, P. and Bock, W.J. (2014) Tuning Properties of Long Period Gratings by Plasma Post Processing of Their Diamond Like Carbon Nano-Overlays. Measurememt Science and Technology, 25, Article ID: 114001. http://dx.doi.org/10.1088/0957-0233/25/11/114001

[29] Ishaq, I.M., Quintela, A., James, S.W., Ashwell, G.J., LopezHiguera, J.M. and Tatamm, R.P. (2005) Modification of the Refractive Index Response of Long Period Gratings Using Thin Film Overlays. Sensors and Actuators B: Chemical, 107, 738-741. http://dx.doi.org/10.1016/j.snb.2004.12.004

[30] Wang, Z., Heflin, J.R., Stolen, R.H. and Ramachandran, S. (2005) Analysis of Optical Response of Long Period Fiber Gratings to Nm-Thick Thin-Film Coatings. Optics Express, 13, 2808-2813. http://dx.doi.org/10.1364/OPEX.13.002808

[31] Villar, I.D., Matías, I.R. and Arregui, F.J. (2005) Optimization of Sensitivity in Long Period Fiber Gratings with Overlay Deposition. Optics Express, 13, 27-69. http://dx.doi.org/10.1364/opex.13.000056

[32] Cusano, A., Iadicicco, A., Pilla, P., Contessa, L., Campopiano, S. and Cutolo, A. (2006) Mode Transition in High Refractive Index Coated Long Period Gratings. Optics Express, 14, 19-34. http://dx.doi.org/10.1364/OPEX.14.000019

[33] Yang, J., Yang, L., Xu, C.Q. and Li, Y. (2007) Optimization of Cladding-Structure-Modified Long-Period-Grating Refractive-Index Sensors. Journal of Lightwave Technology, 25, 372-380. http://dx.doi.org/10.1109/JLT.2006.886720

[34] Korposh, S., Selyanchyn, R., Yasukochi, W., Lee, S.W., James, S.W. and Tatam, R.P. (2012) Optical Fiber Long Period Grating with a Nanoporous Coating Formed from Silica Nanoparticles for Ammonia Sensing in Water. Materials Chemistry and Physics, 133, 784-792. http://dx.doi.org/10.1016/j.matchemphys.2012.01.094

[35] Villar, I.D. (2015) Ultrahigh-Sensitivity Sensors Based on Thin-Film Coated Long Period Gratings with Reduced Diameter, in Transition Mode and near the Dispersion Turning Point. Optics Express, 23, 8389-8398. http://dx.doi.org/10.1364/OE.23.008389

[36] Simões, E., Abe, I., Oliveira, J., Frazão, O., Caldas, P. and Pinto, J.L. (2011) Characterization of Optical Fiber Long Period Grating Refractometer with Nanocoating. Sensors and Actuators B: Chemical, 153, 335-339. http://dx.doi.org/10.1016/j.snb.2010.10.033

[37] James, S.W., Korposh, S., Lee, S.W. and Tatam, R.P. (2014) A Long Period Grating-Based Chemical Sensor Insensitive to the Influence of Interfering Parameters. Optics Express, 22, 8012-8023. http://dx.doi.org/10.1364/OE.22.008012 
[38] Tripathi, S.M., Bock, W.J., Mikulic, P., Chinnappan, R., Ng, A., Tolba, M. and Zourob, M. (2012) Long Period Grating Based Biosensor for the Detection of Escherichia coli Bacteria. Biosensors and Bioelectronics, 35, 308-312. http://dx.doi.org/10.1016/j.bios.2012.03.006

[39] Zou, F., Liu, Y., Deng, C., Dong, Y., Zhu, S. and Wang, T. (2015) Refractive Index Sensitivity of Nano-Film Coated Long-Period Fiber Gratings. Optics Express, 23, 1114-1124. http://dx.doi.org/10.1364/OE.23.001114

[40] Yang, R.Z., Dong, W.F., Meng, X., Zhang, X.L., Sun, Y.L., Hao, Y.W., Guo, X.C., Zhang, W.Y., Yu, Y.S., Song, J.F., Qi, Z.M. and Sun, H.B. (2012) Nanoporous $\mathrm{TiO}_{2} /$ Polyion Thin-Film-Coated Long-Period Grating Sensors for the Direct Measurement of Low-Molecular-Weight Analytes. Langmuir, 28, 8814-8821. http://dx.doi.org/10.1021/la301445h

[41] Korposh, S., James, S., Tatam, R. and Lee, S.W. (2013) Chapter 4: Optical Fiber Long-Period Gratings Functionalised with Nano- Assembled Thin Films: Approaches to Chemical Sensing. In: Cuadrado-Laborde, C., Ed., Current Trends in Short- and Long-Period Fiber Gratings, InTech, 63-86.

[42] Wei, X.T., Wei, T., Xiao, H. and Lin, Y.S. (2011) Terbium Doped Strontium Cerate Enabled Long Period Fiber Gratings for High Temperature Sensing of Hydrogen. Sensors and Actuators B: Chemical, 152, 214-219. http://dx.doi.org/10.1016/j.snb.2010.12.009

[43] Chen, H. and Gu, Z. (2014) Filtering Characteristics of Film-Coated Long Period Gratings Operating at the Phase Matching Turning Point. Optik, 125, 6003-6009. http://dx.doi.org/10.1016/j.ijleo.2014.07.060 